\title{
Association of Digit Ratio With Depression and Hopelessness in Females
}

\author{
Shabnam Aliabadi, Zahra Zendehboodi* \\ Department of Biology, College of Sciences, Shiraz University, Shiraz 71467-13565, Iran.
}

*Correspondence to Zahra Zendehboodi, PhD;Email: zendehboodi@shirazu.ac.ir, zahrazendehboody@yahoo.com

Received August 07, 2021 Accepted September 08, 202 Published online September 30, 2021 as follows: Aliabadi S, Zendehboodi Z. Association of digit ratio with depression and hopelessness in females. Int J Basic Sci Med. 2021;6(3):100104. doi: $10.34172 /$ ijbms.2021.18

\begin{abstract}
Introduction: Depression is regarded as the main cause of individual's incapacity. One of the component of depression is hopelessness. This study was planned to examine if the digit ratio associates with depression and hopelessness status in the Iranian women.

Methods: This cross-sectional study sample included 358 women aged between 20 to 32 years old. The palm side of both hands of individuals was photographed and then the length of index and ring fingers was measured by ImageJ. The Beck's depression inventory II and Beck's hopelessness scale (BHS) were used to measure the levels of depression and hopelessness respectively. ANOVA and Student's $t$ test was applied to compare the study groups in respect to the continuous data.

Results: The results showed that the means of 2D:4D ratio of neither right nor left hands were significantly different between the depression study groups. The same insignificant results were derived with hopelessness status too. However, reanalyzing the data, while combination of depression and hopelessness was considered, showed a significantly lower digit ratio of the right hand in the women whit neither depression nor hopelessness (group 1) compared to the women with moderate/severe depression while holding a degree of hopelessness (group 2) (ratio mean for group 1: $0.978 \pm 0.003$ and for group 2: $0.992 \pm 0.005 ; t=-2.417, P=0.017$ ).

Conclusion: Our data suggested that the 2D:4D ratio of the right hand in the women associates with the severity of depression when accompanied by hopelessness.

Keywords: Women, Depression, Hopelessness, Hand, Digit ratio
\end{abstract}

\section{Introduction}

According to WHO reports, mental disorders are highly common in the world. Globally $4.4 \%$ of the population are estimated to suffer from depression. Depression is regarded as the main cause of individual's incapacity and the major risk factor to suicide death. ${ }^{1}$ Depressed patients generally suffer from chronic medical diseases such as hypertension, arthritis, diabetes, backache, and heart disorders. ${ }^{2}$ The result of a Meta-analysis performed by Abate in 2013 showed that the prevalence of depression in women was higher than men. ${ }^{3}$ One of the component of depression is hopelessness which is described as a state of pessimistic attitude about the future and regarded as a predictor of suicide in patients with mental disorders. Although this cognitive factor is considered as a symptom of depression, evidence indicates that this trait could be distinct from depression and behave independently as it associates with hypertension, mortality, and cancer free of depression. ${ }^{4-6}$

There is strong evidence which confirmed the effect of prenatal androgens on the ratio of the index into the ring finger length (2D:4D). ${ }^{7}$ This ratio in the right hand has been shown to be negatively associated to prenatal ratio of testosterone to estrogen; that is, higher level of prenatal testosterone compares to estrogen results in children with lower ratio of 2D:4D. ${ }^{8}$ Digit ratio has been found as a trait with sexual and ethnical variation ${ }^{9}$ and suggested to be a putative biomarker by much recent evidence, since it has been found to correlate with various physiological, psychological, and pathological features. ${ }^{10}$ It has been found that the lower right hand 2D:4D associate with lung cancer and

(c) 2021 The Author(s); Published by Zabol University of Medical Sciences. This is an open-access article distributed under the terms of the Creative Commons Attribution License (http://creativecommons.org/licenses/by/4.0), which permits unrestricted use, distribution, and reproduction in any medium, provided the original work is properly cited. 
earlier onset of the disease in women. ${ }^{11}$ Also, the right and left hands $2 \mathrm{D}: 4 \mathrm{D}$ have been reported to be higher in the women with the breast cancer. ${ }^{12}$ In men with higher 2D:4D, the neck circumference which is positively correlated with the factors of the metabolic syndrome, has been shown to be higher. ${ }^{13,14}$ The lower digit ratio has been indicated to increase the risk of knee osteoarthritis, and the risk was higher in the females compared to the males. ${ }^{15}$ In a study of self-measured finger lengths and selfreported of age at menarche (AAM) and rate of pubertal development (RPD), the right 2D:4D was showed to be positively and negatively correlated with RPD and AAM respectively. ${ }^{16}$ In both human sex, mental rotation task scores revealed a significant negative association with the right and left hands digit ratio. ${ }^{17}$ It has been shown that homosexual women have significantly lower righthand digit ratio compared to the heterosexual women. ${ }^{18}$ In order to declare the potential association between the prenatal testosterone and mood disorders, many studies have explored the link of the digit ratio with these diseases. ${ }^{10}$ Our present study was planned to examine if the digit ratio, as a sign of antenatal testosterone exposure, associates with depression and hopelessness status in the Iranian women.

\section{Materials and Methods Subjects}

This is a cross-sectional study. The study sample included 358 women aged between 20 to 32 years old. All of the participants were Persian from Fars province, south west of Iran. Exclusion criteria were smoking or alcohol habit, any of disease, and being in menstruation. Sampling was performed in Shiraz city from October through December 2019 and three hundred twenty of individuals participated in our previous study too. ${ }^{19}$

\section{Procedure and Questioners}

To obtain the 2D:4D ratio, the palm side of both hands of all subjects were photographed using the same camera and with the same magnification. All hand photos were taken from the same distance. Then the length of the index and ring fingers (from the tip of the fingers to the bottom line in each finger's basal crease where the fingers join the palm) were measured on the photos using Image J software, and to calculate the $2 \mathrm{D}: 4 \mathrm{D}$ ratio, the index finger (2D) length was divided into the ring finger (4D) length.

To evaluate the levels of depression and hopelessness, the Persian version of Beck's depression inventory II (BDI-II) and Beck's hopelessness scale (BHS) were used respectively. BDI-II is a 21 - question multiple-choice self-report scale with scores ranged from 0 to 63 . Higher scores indicate more sever depressive symptoms. BHS is a 20 -item true or false self-report questionnaire with scores ranged from 0 to 20 . Higher scores reflect greater degree of hopelessness. The cut-off scores suggested for depression are as follows: 0 to 13 , no depression; 14 to 19 , mild depression; 20 to 28 , moderate depression; and 29 to 63, severe depression, and the four hopelessness groups according to the score range are as follows: 0 to 3 , no hopelessness; 4 to 8 , mild hopelessness; 9 to 14 , moderate hopelessness; and 15 to 20 , severe hopelessness. ${ }^{20,21}$ The BDI-II-Persian as a measure of depressive symptoms in nonclinical samples from Iran has been showed to have acceptable test-retest reliability $(r=0.74)$ and high internal consistency (Cronbach's alpha of 0.87). ${ }^{22}$ Also BHS has been reported to have a sufficient reliability (Cronbach's alpha of 0.89 ) and its construct validity was supported through significant correlations with the Patient Health Questionnaire-9, the General Health Questionnaire-12, and the Rosenberg Self-Esteem Scale. ${ }^{23}$

\section{Statistical Analysis}

As the number of participants with sever hopelessness was just 3, this group was pooled to the moderate hopelessness one. The Student's $t$ test and ANOVA was applied to assess the contrast between the study groups in respect to the continuous data. Statistical analysis was done using the SPSS version 22 at a $P<0.05$ significant level.

\section{Results}

The study sample included 358 women aged between 20 to 32 years old (mean \pm SD: $23.2 \pm 2.8$ ). They were university graduated or student or at least achieved the high school diploma. Three hundred twenty-three of the individuals were single and 35 of them were married. The digit ratio means of the right and left hands in the depression and hopelessness study groups were given in Table 1 . According to the ANOVA results, the means of $2 \mathrm{D}: 4 \mathrm{D}$ ratio of neither right nor left hands were significantly different between the depression study groups. The same insignificant results were derived with the hopelessness study groups too.

To examine if the digit ratio associates with the severity of depression when accompanied by hopelessness, we reanalyzed the data with the following condition: we selected the individuals with neither depression nor hopelessness as group 1 and compared their digit ratio with that of individuals who had moderate or severe depression while holding a degree of hopelessness too as group 2. The difference between the digit ratio means of these two groups was examined and the results showed a significantly higher digit ratio of the right hand in the group 2 compared to the group 1, while we did not find any association with the digit ratio of the left hand (Table 2).

It should be mentioned that the score mean of depression in single participants compare to the marrieds was significantly higher (mean \pm SE for singles: $11.42 \pm 0.48$, mean \pm SE for marrieds: $7.60 \pm 1.04, t=2.565, P=0.002$ ) Therefore, to delete the possible effect of marital status, all above analysis were repeated with the sample excluded for 
Table 1. The Mean of Digit Ratio in the Depression and Hopelessness Study Groups

\begin{tabular}{|c|c|c|c|c|}
\hline \multicolumn{2}{|c|}{ Variables } & \multirow{2}{*}{$\frac{\mathbf{n}}{230}$} & \multirow{2}{*}{$\frac{\text { R2D:4D, Mean } \pm \text { SE }}{0.980 \pm 0.002}$} & \multirow{2}{*}{$\frac{\text { L2D:4D, Mean } \pm \text { SE }}{0.976 \pm 0.003}$} \\
\hline \multirow{6}{*}{ Depression } & None & & & \\
\hline & Mild & 73 & $0.977 \pm 0.005$ & $0.973 \pm 0.004$ \\
\hline & Moderate & 40 & $0.981 \pm 0.006$ & $0.966 \pm 0.006$ \\
\hline & Severe & 15 & $1.000 \pm 0.006$ & $0.983 \pm 0.009$ \\
\hline & $\mathrm{F}(d f)$ & & $1.475(3,354)$ & $1.048(3,354)$ \\
\hline & $P$ value & & 0.221 & 0.371 \\
\hline \multirow{5}{*}{ Hopelessness } & None & 195 & $0.977 \pm 0.003$ & $0.976 \pm 0.003$ \\
\hline & Mild & 122 & $0.982 \pm 0.003$ & $0.971 \pm 0.004$ \\
\hline & Moderate/severe & 41 & $0.990 \pm 0.006$ & $0.975 \pm 0.006$ \\
\hline & $F(d f)$ & & $2.317(2,355)$ & $0.606(2,355)$ \\
\hline & $P$ value & & 0.100 & 0.546 \\
\hline
\end{tabular}

$2 \mathrm{D}: 4 \mathrm{D}=$ division of the index finger length into the ring finger length $(R$, right hand; $L$, left hand).

Table 2. Association of the Digit Ratio With the Severity of Depression When Accompanied by Hopelessness

\begin{tabular}{lccr}
\hline Parameters & $\begin{array}{c}\text { Group 1 } \\
\mathbf{n = 1 6 0}\end{array}$ & $\begin{array}{c}\text { Group 2 } \\
\mathbf{n = 4 6}\end{array}$ & $\boldsymbol{t}(\boldsymbol{d f})$ \\
\hline R2D:4D, mean \pm SE & $0.978 \pm 0.003$ & $0.992 \pm 0.005$ & $-2.417(204)$ \\
L2D:4D, mean \pm SE & $0.978 \pm 0.003$ & $0.974 \pm 0.005$ & $0.658(204)$ \\
\hline
\end{tabular}

Group 1: individuals whit neither depression nor hopelessness, Group 2: individuals with moderate/severe depression while holding a degree of hopelessness, $2 D: 4 D=$ division of the index finger length into the ring finger length $(R$, right hand; $L$, left hand).

married individuals, and no substantial difference from the above results was observed.

\section{Discussion}

In the present study the association of the digit ratio with depression and hopelessness status in women was investigated. Now there is enthralling evidence indicating relationship of psychiatric disorders with $2 \mathrm{D}: 4 \mathrm{D}$ ratio. The digit ratio of the right and left hands was reported to be significantly differed in males and females with attention deficit and hyperactivity disorder compared to that in healthy individuals. ${ }^{24}$ Children with autism spectrum disorders showed to have lower right hand digit ratio compared to the normal children. ${ }^{25}$ The patients with schizophrenia showed to have significantly higher right hand digit ratio compared to the control group in both sexes; and the same association was found with the left hand too in females. ${ }^{26}$ Individuals with bipolar disorder showed higher $2 \mathrm{D}: 4 \mathrm{D}$ ratio in the right hand compared to the healthy individuals. ${ }^{27}$ In this study, we did not find relation of the digit ratio with each of depression and hopelessness scores in the women; however, the data indicated the association of $2 \mathrm{D}: 4 \mathrm{D}$ ratio of the right hand with the severity of depression when accompanied by hopelessness. Whereas there is no any report on hopelessness, a body of studies explored the relationship between depression and 2D:4D, though the findings were indecisive. Lautenbacher and Neyse reported no link between depression and digit ratio in a large German sample, ${ }^{28}$ while some other studies found either positive or negative associations. ${ }^{29-32}$ In a study conducted on the female cynomolgus monkeys, the digit ratio of the right and left forelimb hands was significantly higher in the depressed group than that in the normal group. ${ }^{29}$ Higher right hand $2 \mathrm{D}: 4 \mathrm{D}$ ratio was reported to correlate with higher scores of depression in the women but not men. ${ }^{30}$ Other study found that the scores of trait depression was higher in the men with higher digit ratio of the right hand while did not find any association in the women. ${ }^{31}$ In contrast, Vermeersch et al reported a negative association of the digit ratio of the right hand and depression in the males while they did not detect any association in the females. ${ }^{32}$ It is noteworthy that according to the reported evidence, the right hand seems to be more affected by androgenic outcomes for undiscovered reasons. ${ }^{7}$ There was a limitation to the present study. Since the study was conducted on apparently healthy individuals, the frequency of participants with severe depression and hopelessness was very low which may lead to lose the significant results when these two mood states were analyzed separately.

\section{Conclusion}

In conclusion, our data support the idea of more reactivity of the right hand to the androgen, and suggest the association of the right-hand digit ratio with the severity of depression when accompanied by hopelessness in the women. If these preliminary results are approved by further investigations, the $2 \mathrm{D}: 4 \mathrm{D}$ ratio may use as a marker of susceptibility to the depression in the Iranian 
women. As far as we know, this study is the first of its kind from Iran, although because of small sample size of the group 2, the results demand to be confirmed in larger surveys. Further inspections are required to clarify the equivocal relation between depression and digit ratio as a sign of antenatal testosterone exposure.

\section{Ethical Approval}

This study was authorized by ethics committee of Shiraz University, Iran (ECBDE-SU-9-6177616), and all participants declared their consent to participate in the study.

\section{Competing Interests}

The authors have no conflict of interest to declare.

\section{Authors' Contribution}

Obtaining the data, statistical analyses, and drafting of the manuscript, SA; Study design, revising the manuscript and approving the final manuscript, ZZ.

\section{Financial Support}

This study was supported by Shiraz University.

\section{Acknowledgements}

This study was supported by Shiraz University (grant No.99GCB1M256246). The authors greatly thank all the individuals who consented to participate in this study.

\section{References}

1. World Health Organization (WHO). Depression and Other Common Mental Disorders: Global Health Estimates. Geneva: WHO; 2017. https://apps.who.int/iris/bitstream/ handle/10665/254610/WHO-MSD-MER-2017.2-eng. pdf? sequence $=1$.

2. Cassano P, Fava M. Depression and public health: an overview. J Psychosom Res. 2002;53(4):849-857. doi:10.1016/s0022-3999(02)00304-5

3. Abate $\mathrm{KH}$. Gender disparity in prevalence of depression among patient population: a systematic review. Ethiop J Health Sci. 2013;23(3):283-288. doi:10.4314/ejhs. v23i3.11

4. Dunn SL. Hopelessness as a response to physical illness. J Nurs Scholarsh. 2005;37(2):148-154. doi:10.1111/j.15475069.2005.00027.x

5. Everson SA, Goldberg DE, Kaplan GA, et al. Hopelessness and risk of mortality and incidence of myocardial infarction and cancer. Psychosom Med. 1996;58(2):113-121. doi:10.1097/00006842-199603000-00003

6. Everson SA, Kaplan GA, Goldberg DE, Salonen JT. Hypertension incidence is predicted by high levels of hopelessness in Finnish men. Hypertension. 2000;35(2):561-567. doi:10.1161/01.hyp.35.2.561

7. Breedlove SM. Minireview: organizational hypothesis: instances of the fingerpost. Endocrinology. 2010;151(9):4116-4122. doi:10.1210/en.2010-0041

8. Lutchmaya S, Baron-Cohen S, Raggatt P, Knickmeyer R, Manning JT. 2nd to 4th digit ratios, fetal testosterone and estradiol. Early Hum Dev. 2004;77(1-2):23-28. doi:10.1016/j.earlhumdev.2003.12.002

9. Manning JT, Stewart A, Bundred PE, Trivers RL. Sex and ethnic differences in 2 nd to 4th digit ratio of children. Early Hum Dev. 2004;80(2):161-168. doi:10.1016/j. earlhumdev.2004.06.004

10. Fusar-Poli L, Rodolico A, Sturiale S, et al. Second-to-fourth digit ratio (2D:4D) in psychiatric disorders: a systematic review of case-control studies. Clin Psychopharmacol Neurosci. 2021;19(1):26-45. doi:10.9758/ cpn.2021.19.1.26

11. Kasielska-Trojan A, Manning JT, Antczak A, et al. Digit ratio (2D:4D) in women and men with lung cancer. Sci Rep. 2020;10(1):11369. doi:10.1038/s41598-020-68239-0

12. Mendes PH, Gomes AC, Soares PB, et al. Digit ratio (2D:4D) is associated with breast cancer. Int J Cancer Ther Oncol. 2016;4(3):438. doi:10.14319/ijcto.43.8

13. Fink B, Manning JT, Neave N. The 2nd-4th digit ratio (2D:4D) and neck circumference: implications for risk factors in coronary heart disease. Int J Obes (Lond). 2006;30(4):711714. doi:10.1038/sj.ijo.0803154

14. Ben-Noun L, Laor A. Relationship of neck circumference to cardiovascular risk factors. Obes Res. 2003;11(2):226-231. doi:10.1038/oby.2003.35

15. Zhang W, Robertson J, Doherty S, et al. Index to ring finger length ratio and the risk of osteoarthritis. Arthritis Rheum. 2008;58(1):137-144. doi:10.1002/art.23237

16. Manning JT, Fink B. Is low digit ratio linked with late menarche? evidence from the BBC internet study. Am J Hum Biol. 2011;23(4):527-533. doi:10.1002/ajhb.21186

17. Peters M, Manning JT, Reimers S. The effects of sex, sexual orientation, and digit ratio (2D:4D) on mental rotation performance. Arch Sex Behav. 2007;36(2):251-260. doi:10.1007/s10508-006-9166-8

18. Williams TJ, Pepitone ME, Christensen SE, et al. Finger-length ratios and sexual orientation. Nature. 2000;404(6777):455456. doi:10.1038/35006555

19. Aliabadi S, Alvyar L, Zendehboodi Z. The association of hot/cold status of temperament with depression and hopelessness scores in females. Curr Tradit Med. 2021;7(4):582-585. doi:10.2174/1568026620999201202 151037

20. Groth-Marnat G, Wright AJ. Handbook of Psychological Assessment. New Jersey: Wiley; 2016.

21. Beck AT, Weissman A, Lester D, Trexler L. The measurement of pessimism: the hopelessness scale. J Consult Clin Psychol. 1974;42(6):861-865. doi:10.1037/h0037562

22. Ghassemzadeh $H$, Mojtabai R, Karamghadiri N, Ebrahimkhani N. Psychometric properties of a Persianlanguage version of the Beck Depression Inventory-Second edition: BDI-II-PERSIAN. Depress Anxiety. 2005;21(4):185192. doi: $10.1002 /$ da. 20070

23. Aloba O, Olabisi O, Ajao O, Aloba T. The Beck Hopelessness Scale: factor structure, validity and reliability in a sample of student nurses in south-western Nigeria. Int Arch Nurs Health Care. 2016;2(4):056. doi:10.23937/24695823/1510056

24. Buru E, Gözil R, Bahçelioğlu M, Özkan S, İşeri E. Evaluation of the hand anthropometric measurement in ADHD children and the possible clinical significance of the 2D:4D ratio. East J Med. 2017;22(4):137-142. doi:10.5505/ ejm.2017.73792

25. Baharara J, Hojjati $M$, Rasti $H$, Sarabi Jamab $M$. The ratio of second to fourth digit length (2D:4D) in children with autistic disorder. Int J Pediatr. 2014;2(2-4):5-11. doi:10.22038/ijp.2014.3420

26. Qian W, Huo Z, Lu H, Sheng Y, Geng Z, Ma Z. Digit ratio (2D:4D) in a Chinese population with schizophrenia. 
Early Hum Dev. 2016;98:45-48. doi:10.1016/j. earlhumdev.2016.05.003

27. Tegin C, Canan F, El-Mallakh RS. The 2 nd to 4th digit ratios (2D:4D) in patients with bipolar disorder. J Affect Disord. 2019;259:27-30. doi:10.1016/j.jad.2019.08.011

28. Lautenbacher LM, Neyse L. Depression, neuroticism and 2D:4D ratio: evidence from a large, representative sample. Sci Rep. 2020;10(1):11136. doi:10.1038/s41598-02067882-x

29. Li W, Luo LY, Yang X, et al. Depressed female cynomolgus monkeys (Macaca fascicularis) display a higher second-tofourth (2D:4D) digit ratio. Zool Res. 2019;40(3):219-225. doi:10.24272/j.issn.2095-8137.2019.022

30. Smedley KD, McKain KJ, McKain DN. 2D:4D digit ratio predicts depression severity for females but not for males. Pers Individ Dif. 2014;70:136-139. doi:10.1016/j. paid.2014.06.039

31. Bailey AA, Hurd PL. Depression in men is associated with more feminine finger length ratios. Pers Individ Dif. 2005;39(4):829-836. doi:10.1016/j.paid.2004.12.017

32. Vermeersch $H, T^{\prime}$ Sjoen $G$, Kaufman JM, Vincke J. 2D:4D, sex steroid hormones and human psychological sex differences. Horm Behav. 2008;54(2):340-346. doi:10.1016/j.yhbeh.2008.02.017 